\title{
Comparison of tomato root distributions by minirhizotron and destructive sampling
}

\author{
Rui M.A. Machado ${ }^{1}$ \& Maria do Rosário G. Oliveira \\ Universidade de Évora, Departamento de Fitotecnia, Apartado 94, 7002-554 Évora, Portugal. ${ }^{1}$ Corresponding \\ author*
}

Key words: processing tomato, root length density and intensity, root observation tubes

\begin{abstract}
Calibration of minirhizotron data against root length density (RLD) was carried out in a field trial where three drip irrigation depths: surface (R0) and subsurface, $0.20 \mathrm{~m}$ (RI) and $0.40 \mathrm{~m}$ depth (RII) and two processing tomato cultivars: 'Brigade' (CI) and 'H3044' (CII) were imposed. For each treatment three minirhizotron tubes were located at 10,37.5 and $75 \mathrm{~cm}$ of the way from one plant row to the next. Roots intersecting the minirizotrons walls were expressed as root length intensity $\left(L_{\mathrm{a}}\right)$ and number of roots per unit of minirhizotron wall area $\left(N_{\mathrm{ra}}\right)$. Root length density (RLD) was calculated from core samples taken for each minirhizotron tube at two locations: near the top of the minirhizotron (BI) and $15 \mathrm{~cm}$ apart from it, facing the minirhizotron wall opposite the plant row (BII). Minirhizotron data were regressed against RLD obtained at BI and BII and with their respective means. The results show that for all the situations studied, better correlations were obtained when RLD was regressed with $L_{\mathrm{a}}$ than with $N_{\text {ra. }}$. Also was evident that the relationship between $L_{\mathrm{a}}$ and RLD was strongly influenced by the location of soil coring. RLD was correlated with $L_{\mathrm{a}}$ trough linear and cubic equations, having the last ones higher determination coefficients. For instance at $10 \mathrm{~cm}$ from the plant row when values from the top layer $(0-40 \mathrm{~cm})$ were analysed separately, $L_{\mathrm{a}}$ was significantly regressed with RLD measured at BII and described by the equations: RLD $=0.5448$ $+0.0071 L_{\mathrm{a}}\left(R^{2}=0.51\right)$ and $\mathrm{RLD}=0.4823+0.0074 L_{\mathrm{a}}+8 \times 10^{-5} L_{\mathrm{a}}{ }^{2}-5 \times 10^{-7} L_{\mathrm{a}}{ }^{3}\left(R^{2}=0.61\right)$. Under the $40 \mathrm{~cm}$ depth the highest coefficients of determination for the linear and cubic equations were respectively 0.47 and 0.88 , found when $L_{\mathrm{a}}$ was regressed with RLD measured at BI. For minirhizotrons located at $75 \mathrm{~cm}$ from the plant row and for location BI it was possible to analyse jointly data from all depths with coefficients of determination of 0.45 and 0.59 for the linear and cubic equations respectively.
\end{abstract}

Abbreviations: $\mathrm{BI}$ - hole at the top of the minirhizotron; BII - hole $15 \mathrm{~cm}$ from the top of the minirhizotron, facing the minirhizotron wall opposite the plant row; $L_{\mathrm{a}}-$ Root length intensity; $N_{\text {ra }}$ - Number of root counts per unit of minirhizotron wall area; RLD - root length density

\section{Introduction}

The minirhizotron method avoids one of the most important constraints on root studies, the labour and time involved in sampling and handling roots for posterior quantification. Another advantage of this method is that individual roots can be followed over time, which allows for root dynamics studies (Smit et al., 2000). With this method, root growth and distribution along the soil profile can be estimated from images recor-

\footnotetext{
* FAX No: +351-266-71-1163. E-mail: rmam@uevora.pt
}

ded at different depths on the minirhizotron surface, but to estimate a bulk soil parameter like root length per unit volume of soil (root length density, RLD) either a theoretical transformation is required or a calibration method is carried out. However, in result of tube interface influence on soil growing conditions some discrepancies between minirhizotron and soil coring data are pointed to by several authors and different explanations have been given for this (Smit et al., 2000). Also, the fact that a positive correlation between minirhizotron data and soil coring is only achieved when data from the uppermost (e.g., the 